\title{
The Value of Color Research in Brand Strategy
}

\author{
Meagan K. Cunningham \\ College of Arts and Sciences, Seton Hall University, South Orange, NJ, USA \\ Email: meagankristen@gmail.com
}

How to cite this paper: Cunningham, M.K. (2017) The Value of Color Research in Brand Strategy. Open Journal of Social Sciences, 5, 186-186.

https://doi.org/10.4236/jss.2017.512014

Received: November 23, 2017

Accepted: December 23, 2017

Published: December 26, 2017

Copyright $\odot 2017$ by author and Scientific Research Publishing Inc. This work is licensed under the Creative Commons Attribution International License (CC BY 4.0).

http://creativecommons.org/licenses/by/4.0/

\begin{abstract}
Is color more than a design? The following research discusses the science of color to consumer perception and the value of that color research to consumer-brand relationships. Specifically, it examines how color influences consumers' perception and how brands strategically utilize color to distinguish themselves amongst competitors, establish an identity, promote an image, and foster relationships with its consumers. To examine the significance of color to consumer perception and brand imagery, a nonrandom sample of men and women between the ages of 18 and 37 years old participated in a focus group that included color-centric photos and a survey. The results of the nonrandom sample also show that colors used in branding influence consumers' perception, are used to identify products, and carry meaning that's evolved into a relationship between the brand and the consumer. These findings were consistent with previous research that found through color, brands effectively establish an identity, communicate a mood, and form a relationship with consumers (Labrecque and Milne, 2011) [1]. The results of the survey also reveal that consumers don't rely solely on color when recognizing a branding and more can be done to examine how integral color is to manufacturing brand-consumer relationships.
\end{abstract}

\section{Keywords}

Brand Strategy, Brand Personality, Color, Communication, Visual Thinking

\section{Introduction}

To some consumers, color is merely a decorative trait. However, in marketing strategies, color is used by brands to reach consumers on a deeper level and stand out in the market amongst competitors. The objective of this article is to analyze brands that have benefited from color strategy, while providing psychological insight to brands and entrepreneurs entering the business market. Brandeo (2013) [2] explains that a brand is the sum of all associations, feelings, 
perception, and attitudes that consumers relate to both the intangible and tangible characteristics of a company, product or service. In the retail, food and beverage, home improvement, and pharmaceuticals, color is strategically used to attract consumers, communicate a personality, status, and build a relationship with consumers based on loyalty.

To ensure color is most effective, brands wanting to optimize success, should seek color research that can best meet their objectives of appealing to consumers. In the 1980s, an emergence of studies showed consumer-brand relationships came with financial values, which brought the concept of a brand image to mainstream marketing theories, and encouraged major brands to spend more time and attention to the science of color and what it meant to consumers (Grimes and Doole, 1998: p. 800) [3].

The color-emotion pairings are experienced by consumers through a neurologic scientific process of cognition, where consumers' sense of sight results in the brain's processing of color as a form of information. In a 2007 study, it was found that "associative learning of visual information develops during early stages of visual processing as a key mechanism for quick decision making" (Labrecque and Milne, 2011: p. 713) [1]." The validity of color-research dates as far back as $1971 \mathrm{n}$ and shows there is an association between color, emotion and perception (Grimes and Doole, 1998) [3] and because the majority of colors are paired with an emotion and physical attribute, brands and consumers who wish to portray themselves in a specific manner, choose colors that pair with specific connotations. For example, brands and consumers that want to be viewed as young and vibrant, tend to choose bright colors, while those who desire to appear sophisticated and wealthy, choose colors like black, purple or beige.

In turn, brands can utilize color to provide information to the consumer about a product attributes such as price and quality, while influencing consumers' opinion about a business' product or service. Notably, while color-emotion pairings studies are limited, the effects of colors remain relatively consistent across studies can be sustained across national boundaries (Grimes and Dooole, 1998: p. 799) [3]. Using the appropriate colors in branding allows brands to develop an identity and build a brand relationship with consumers, that's worth the investment. The value of color psychology is so important to marketing strategies that it has caused some corporations to spend millions of dollars to further distinguish themselves against competition with color rebranding campaigns, and other corporations to take legal action against those who may threaten its brand's trademarked color. While some corporations choose to take advantage of color research, those ones that do not can risk mediocrity.

Having both physical and emotional properties, color provides information to consumers about a corporation's brand. From the time a consumer sees a display in a store window up to the purchasing decision, the association of emotion and color are important to corporate brands. Within seconds, color can influence a consumer to form an opinion about a business' product or service before any other additional information has been provided (Goodgold, 2010: p. 99) [4]. 
Research on the physical and emotional properties of color is crucial to the development of brands and marketing strategies as it is important to assess what it is consumers are seeing.

\section{Perception and Behavior}

When used strategically, the appropriate color that is chosen to represent a brand can be very effective as perception as "the brain's organizing and interpreting of sensory information from the environment to give it its meaning" (Ndom, Elegbeleye and Ademoriti, 2011: p. 169) [5]. How an organization is perceived can be a result of how it communicates visually through its brand's color.

Contrary to lettered logos, tag lines and other components used in branding, color, including its hue and saturation, is perceived and translated by the brain, without context. LaBrecque and Milne (2011) further explain that if consumers encounter a new brand logo and there are no brand associations (like shapes) existing in memory, the resulting perception of that brand's personality is primarily based on the brain's activated association triggered by the referential meaning of the color (p. 713) [1].

Fundamentally, colors appeal to consumers' sense of sight, and "vision is the dominant sensory for man" (Ndom, Elegbeleye and Ademoriti, 2011: p. 171) [5]. Unlike the flexibility of the body's other four, color has the ability to trigger an emotional response, carry an associated meaning and be used as a means of identification. In the eye of consumers, color is more than a pretty design-it's a science. To perceive color is a cognitive process (Ndom, Elegbeleye and Ademoriti) [5], increasing brain activity, establishing a pattern of memory and evoking emotion.

Consumers process color in wavelengths, or measurements of light (Aslam, 2006: p. 17) [6]. Then, that "color is light carried on wavelengths absorbed by the eyes that the brain converts into colors that we see" (Singh, 2006: p. 783) [7]. The color red has the longest wavelength while purple has the shortest. Additionally, colors that are alike such as red, yellow and orange have similar wavelengths; while colors like purple, blue and brown have their own comparable wavelengths. These measurements of light, or the vision of color, react with nerves in the body and can stimulate arousal, induce a change in attitude and thus, produce an emotional response, impacting consumer behavior (LaBrecque and Milne, 2011: p. 713) [1].

Researchers have found that the emotional responses triggered by colors are consistent. The color red is linked to exciting, yellow to playful or cheerfulness, green to feelings of security, purple to connotations of luxury and wealth, and blue to intelligence, tranquility, communication and trust (Grimes and Doole, 1998; LaBrecque and Milne, 2011; Aslam, 2006) [3] [6].

Tavassoli (2011) [8] explains that consumer perception is not primarily dependent on words because perception automatically results from the representation of color in visual short-term memory. When consumers see a color, and it is 
processed from wavelengths to emotions, they will naturally assign meanings or values to what the color cognitively represents. Using color, consumers retain information, interpret identity and form an emotion-based response that results in patterns of behavior. Therefore, "the systematic relationship between color and emotions and psychological functioning provoke people to choose consistent color-emotion pairings" (Labrecque and Milne, 2011: p. 713) [1].

To strategically drive sales, Singh (2006) points out that formal restaurants use blue to calm and relax customers, leading them to stay longer, and eat larger meals; while the color yellow is famously used by fast food restaurants to catch customers' attention and encourage them to eat (p. 785) [7]. Further spotlighting the cognitive effects of color on consumer behavior, Alpert reports "patrons are 15 percent more likely to return to stores with blue color schemes than to stores with orange [9]." Understanding these research findings can enable corporations to use color to affect consumer perception and develop strategic marketing tactics to alter consumer behavior. In this way, as Grimes and Doole (1998) explain "brands have gone beyond the promotion of tangible and functional benefits and into the mystical realms of emotion, perception and image (p. 799) [3].”

\section{Communicating an Image}

To consumers, color can be used to communicate a status, attitude or key message. Consumers rely on their sense of color to retrieve information but also to give information. As a part of the cognitive processing of color, Aslam (2006) explains, "people tend to choose the colors of their cars, homes, clothes and even sports shoes depending on how they wish to present themselves (p. 24) [6]." By utilizing this information, brands can use a color to target a specific audience and communicate an identity or personality trait.

Consumers' interest in using a brand as a means of self expression positions businesses to use color research to create marketing strategies that build brand recognition, brand personality and brand loyalty. In an Italian advertisement, Volkswagen Car Company showed a black sheep in a flock in Italy to portray the VW Golf owner as an independent self-assured person, because in Italy, a black sheep is a symbol of independence (Aslam, 2006: p. 26) [6]. Volkswagen targeted people looking to communicate an image of self-sufficiency and confidence. The strategic use of color in this advertisement appealed to consumer perception and communicated an image consumers would want to replicate.

Another organization that was able to reach a specific target audience by using color is theSusan G. Komen foundation that has raised awareness of breast cancer using the color pink (Figure 1) [10]. "Pink has become the signature color of women, because they embrace it (Goodgold, 2010: p. 102) [4].” By associating the color pink with femininity, Susan G. Komen has been able to engage and mobilize millions of women and advocates across the United States.

Although colors are beneficial, they shouldn't just be picked on a simple spectrum, saturation, or the brightness or dullness of a color, should also be considered. 


\section{susang.}

Figure 1. Susan G. Komen breast cancer awareness logo.

Aslam (2006) makes a point of visual branding noting simple colors are vibrant and playful like, Toys 'R' Us and McDonald's, whereas sophisticated colors [likeblack or burgundy (Alpert, 2013)] seen in brands like Laura Ashley (home furnishings and décor) and Jaguar denote elegance (p. 25) [6] [9]. For consumers wanting to communicate elegance, they become attached to a brand's visual identity and develop an increased likeability with that image. Laura Ashley and Jaguar communicate an identity of luxury and class in order to target a higher demographic. If Laura Ashley and Jaguar used only text to communicate sophistication, building an outward expressive brand, with loyalists could be more challenging. The brand personality and the effectiveness of color allow for corporate brands to implement color into marketing strategies that shape consumer perception, behavior and purchase intent. Grimes and Doole (1998) suggest "researchers all over the world have begun to recognize the importance of color in reaching increasingly sophisticated customers on a deeper level" (p. 799) [3].

As a part of a marketing strategy, Singh (2006) emphasizes "research relating to choice of colors should be conducted and concluded before launching a product, as the wrong color choice can have negative impact on the image of the product and the company" (p. 786) [7]. Researching the perception of color and its effects on consumer behavior can enable brands to reach a specific audience and communicate a desired image that brand loyalists embrace. Ndom, Elegbeleye and Ademoriti add that the "knowledge of perception helps understand humans better, and design systems appropriately (p. 169) [5]." Because color has consistency in emotions, knowing what influences consumer behavior, attracts consumers, increases likeability and maintains brand loyalists could strongly position a brand against its competitors. The exponential value of color psychology is demonstrated in color rebranding campaigns and legal cases that cherish consumer perception.

\section{Major Marketing}

For marketers, the perception process must first begin with capturing the consumer's attention. Goodgold (2010) found that "color is a powerful tool; within three seconds of seeing something we [consumers] register its color (p. 99) [4]." Using appropriate visual branding, color can alter a brand message, image or appeal, or elicit a physical response, rather than psychological one.

Madden, Hewitt, and Roth (2000) found that after Wagner Color Research Institute discovered orange was associated with cheapness, it advised Weinerschnitzel, a fast food restaurant, to add orange to the visual brand of its buildings 
to convey a message that it sold inexpensive hot dogs [11].

Weinerschnitzel reported a 7 percent increase in sales after it added orange. Therefore, Weinerschnitzel was able to effectively communicate its message by using only color (Madden, Hewitt, and Roth, 2000: p. 91) [11].

One of the most expensive endeavors, where a corporation placed heavy financial value on color, was the case of Pepsi versus Coca-Cola.

In 1996, Pepsi launched a $\$ 500$ million color rebranding initiative called "Project Blue" (Figure 2) (Tavassoli, 2001: p. 104) [8] [12] [13].

The campaign was a worldwide venture to distinguish its "electric blue" color against Coca-Cola's bold red. LaBrecque and Milne (2011) found that as a part of its "Project Blue," one of Pepsi's major marketing strategies included painting an Air France Concorde jet blue (p. 711) [1]. Pepsi's color rebranding strategy signified the move away from a "traditional color in order to create new color associations by choosing blue" (Aslam, 2006: p. 23) [6].

Another costly campaign is Owens Corning fiberglass insulation manufactures. Over the course of 10 years Owens Corning spent over $\$ 42$ million on a color rebranding campaign to build a unique brand identity using the color pink. The "get pink" campaign yielded overwhelming consumer association of pink insulation with the Owens Corning brand, that was able to distinguish the insulation it sells against insulation competitors who use the customary yellow insulation (Zaichkowsky, 2010: p. 555) [14].

Both Pepsi and Owens Corning invested over tens of millions of dollars on color to alter consumer perception, reposition its brand, and influence consumer-purchasing behavior. By rebranding with a distinctive color, Labrecque and Milne (2011) explains that "a brand can establish an effective visual identity, form relationships with a target market and position itself among competitors in the marketplace (p. 711) [1].” Color science doesn't just start and end with a product. It was found that warm colors (red, orange and yellow) are better in physically attracting customers (Aslam, 2006), while cooler colors, such as blue and green, are better for in-store displays and easier on the customer when making a purchasing decision [6].

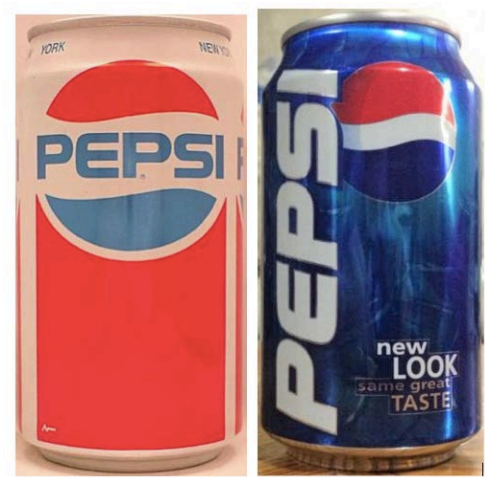

Figure 2. Pepsi's dominant brand colors in 1987 vs. 1997 [12] [13]. 
The value of color to consumers isn't limited to retail, food and beverage or home improvement consumers. Pharmaceutical manufacturers also use color to appeal to consumers' means of identification. Nuprin was the first pharmaceutical drug to make an effort to own rust-color pills (Goodgold, 2010: p. 96) [4], for its ibuprofen product. In fact, Goodgold (2010) found that patients often tell their doctors what medications they're using by the color [4]. The manufacturer Levoxyl brands the dosage of its pills with color-a $5 \mathrm{mg}$ Levoxyl might be yellow, but a $10 \mathrm{mg}$ Levoxyl may be blue. This identity allows for doctors and patients to have a better understanding of the prescribed medication. Although branding medication isn't a $\$ 42$ million campaign, the value of color to the identity process is important manufactures everywhere. Some have even gone through legal measures to protect their colors from those of its competitors, through trademark registration.

In the past, trademarks have been reserved for names and logos, but in more recent decades, "companies have registered colors as trademarks after demonstrating that a specific color has become so consistently linked with a specific brand, that it has acquired secondary meaning, which is assessed in court" (Hoek and Gendall, 2010, p. 317) [15]. Then, to establish a color's distinctive association with a brand, counsel must define the color using the international the Pantone system and produce evidence about the brand's use of the color, including the length of time the color's been used, the extent of advertising that's taken place, and the use of that color by rivals." (Hoek and Gendall, 2010: p. 317) [15].

The first brand to successfully trademark a color was Qualitex in 1995. Qualitex successfully argued that the "green-gold," that's on its dry-cleaning pads had a distinctive association with its particular brand and that competitors using the "green-gold" were trying to pass off the competing products as the Qualitex brand (Hoek and Gendall, 2010: p. 317).

More recently, in 2008 British confectioner Cadbury, submitted a court application to register its signature color purple, known as Panteone 2385c, which it had successfully trademarked in 1995 for its chocolate bars specifically. Although Swiss confectioner Nestlé challenged Cadbury's trademark petition in court, and won the case in 2013, Cadbury was able to put a legal stop to all other confectionary companies using its purple because from various tests involving focus groups and the color wheel, research revealed consumers strongly associated Cadbury and purple (BBC News, 2013; Hoek and Gendall, 2010: p. 317) [16] [15]. The main focus of these cases centered on importance of color to consumers' perception and an assigned meaning or value of the product. Both organizations proved that the distinctive use of color used on products were pertinent to their brand's identity and valued by their consumers.

As colors are used in branding strategies to establish an identity or a means of communicating a personality, research shows consumers have a unique brand experience, evoking feelings and cognitions that result in consistent behavior or 
loyalty (Brakus, Schmitt, and Zarantonello, 2009: p. 53) [17]. For consumers brand loyalty is ultimately seen in purchasing decisions, where one product is valued more than the other, but can develop from a reputation of quality of what consumers perceive is being communicated through that brand. With Qualitex and Owens-Corning, consumers became loyalists through their experience with the paired color, giving the product second meaning.

By brands going to multimillion-dollar measures to distinguished or trademark themselves with color, it's acknowledged that the value of color research is critical consumer perception, behavior and brand identity as a whole.

\section{Methodology, Results, and Discussion}

To test color to consumer perception and brand identity, a nonrandom convenience sample of 20 North Jersey men and women between the ages of 18 and 37 years old participated in a focus group. Using color-centered advertisements and photos, partnered with a survey questionnaire, this study examined consumer perception and behavior with color and corporate brand identity. The results of this study demonstrate the ability of color to provide visual information to consumers without words or lettered logs. This study also shows color is used as a primary tool in identification and has the ability to influence perception about price, quality and brand personality. To understand what participants use to make decisions, some questions included two parts.

To evaluate brand identity in retail clothing, questions include two sets of side-by-side advertisements that are comparable in content. The advertisements in set one asked participants to identify which of the two undergarment advertisements is Victoria's Secret. The results show that 85 percent of participants recognize Victoria's Secrets' brand. When asked what tools were used to identify the brand, 20 percent recognize the model, 55 percent recognize the fabric or style, 20 percent recognized a distinguishable color and 0.05 percent feel all three options contribute to the brand.

To show consistency in color-emotion pairings, as described in previous research, advertisements in set two show women in different color beach attire. Advertisement one features a woman in a bright yellow and turquoise beach cover-up, while advertisement two features a woman in a pastel turquoise bikini and a scarf. Out of the 20 participants 55 percent perceived advertisement one as fun, 15 percent perceived it as serious, 30 percent perceived it as exciting and none found it relaxing. Contrary to advertisement one, 50 percent perceived advertisement two as relaxing, 40 percent perceived it as serious, 0.05 percent perceived it as fun and 0.05 percent perceived it as exciting. To identify the advertisements, 25 percent used the model, 25 percent use color, 30 percent use fabric and 15 percent use "other" or style.

To further examine consumer's ability to identity a brand by color, participants looked at four colors and were asked to match each color to an unlabeled brand of laundry detergent. The results show 85 percent of participants identify brands of laundry detergent by color, while 15 percent could not. 
To show the use of color as a primary tool in the description process, this study shows what participants use color to give information about a lost item. The results show 45 percent express they would use color and brand, 25 percent say they would use just the brand name, 15 percent would use just color and $0.05 \%$ would use shape.

Using photos of two restaurants, the study shows the effects of color on consumer perception and how it influences behavior. When selecting restaurant $\mathrm{A}$, an eat-in fast food chain, or B a cooler toned café-like establishment, as a place that participants would stay longer, 65 percent say restaurant B and $35 \%$ say restaurant B. Although restaurant A is a fast food place and isn't preferred by the majority, the café style restaurant B was also not everyone's' choice.

To further study examine consumer perception, a scenario of Target changing its red to a brown show the opinion of participants about corporate color rebranding. If Target rebranded from red to brown, 55 percent would find it disagreeable, while 30 percent would find it confusing and 15 percent wouldn't have an opinion. To gage the personal relationships with color and corporate brands, participant responses to a personal favorite brand changing its color, show 25 percent say they'd feel confused, 30 percent would find it disagreeable and 33 percent wouldn't have an opinion.

This study examines how color affects consumer perception and the use of color in corporate branding. Results show that while some participants struggle to identify clothing brand advertisements, participants are able to recognize laundry detergent. Measuring brand likeability, the results show participants would find it disagreeable if Target changed its red color to brown, although the participants expressed that they are unsure how they'd feel if their favorite brand changed its current color to a different color. When it comes to using color as a tool in the description process, the majority of participants do find color a reliable mechanism. In consumer perception and behavior, the results show that people are more like to spend more time at a café, (restaurant B) because it appears to be more comfortable, however a few participants felt that the fast-food establishment (restaurant A) seating also looked comfortable. Many of the results are conclusive because the majority of nonrandom convenience sample show color does affect consumer perception, however a select few of those participants express that there are other factors that influence perception, behavior and brand identity.

Limitations in this paper include sources that are peer reviewed. Furthermore the methodology used a nonrandom sample of 20 North New Jersey participants and more insight could be gained from a more representative and scientific sample. The research lacks data of brands that suffer from not using color research and consumer perception.

\section{Conclusion}

The review of literature shows that color is vital to the communication and relationship building process to both consumers and brands. Furthermore, the effect 
of color on consumer perception has been financially measured up to $\$ 500$ million and defended in international courts. Although the effect of color on consumer perception shows that color does carry meaning, additional research to evaluate if consumer loyalty or perception changes, with the change of a brand's color. Overall, the literature shows that color can trigger an emotional response, carry associated and intrinsic meanings, as well as influencing consumers' perception about what a brand communicates, and whether it's familiar. The ability for color to alter purchase intent can be beneficial to in branding strategies around the world. While many brands value color science, additional research on organizations that don't consult color research should also be further studied. More research can also be done to see how colors are used by brands to manipulate consumer perception, due to the intrinsic cognitive associations, i.e. brands using green to communicate naturalness or an environment-safe identity. Nonetheless color research should be utilized by any brand wanting to connect with consumers and stakeholders on a deeper level. After all, "when color has a specific, predetermined function that acts to support the overall strategy, your marketing effort can do all you've designed it to do" (Grimes and Doole, 1998: pp. 799-800) [3].

\section{References}

[1] Labrecque, L.I. and Milne, G.R. (2011) Exciting Red and Competent Clue: The Importance of Color in Marketing. Journal of Academy of Marketing Science, 40, 711-727.

[2] Kotelr, P. (2003) Brand-Defined. Brandeo. http://www.brandeo.com/node/938

[3] Grimes, A. and Doole, I. (1998) Branding: A Cross Cultural Comparison of the UK and Taiwan. Journal of Marketing Management, 14, 799-817. https://doi.org/10.1362/026725798784867581

[4] Goodgold, L. (2009) Red Fire Branding: Create a Hot Personal Brand and Have Customers for Life. WBusiness Books, El Monte, CA.

[5] Ndom, R.E., Elegbeleye, A. and Ademoroti, A. (2011) The Effect of Colour on the Perception of Taste, Quality and Preference of Fruit Flavored Drinks. http://www.readperiodicals.com/201109/2464158461.html

[6] Aslam, M.M. (2006) Are You Selling the Right Colour? A Cross-Cultural Review of Colour as a Marketing Cue. Journal of Marketing Communications, 12, 15-30. https://doi.org/10.1080/13527260500247827

[7] Singh, S. (2006) Impact of Color on Marketing. Management Decision, 44, 783-789. https://doi.org/10.1108/00251740610673332

[8] Tavassoli, N.T. (2001) Color Memory and Evaluations for Alphabetical and Logographic Brand Names. Journal of Experimental Psychology: Applied, 7, 104-111. https://doi.org/10.1037/1076-898X.7.2.104

[9] Alpert, Y.M. (n.d.) How Color Affects Your Spending. Real Simple. http://www.realsimple.com/work-life/money/color-psychology-00100000097166/in dex.html

[10] Komen, S.G. (2017) Northwest Ohio. http://komennwohio.org

[11] Madden, T.J., Hewett, K. and Roth, M.S. (2000) Managing Images in Different Cul- 
tures: A Cross-National Study of Color Meanings and Preferences. Business Information, News, and Reports.

http://business.highbeam.com/138253/article-1G1-69978963/managing-images-diff erent-cultures-crossnational-study

[12] Can Museum (2010) Pepsi-Cola-354mL-United States. http://www.canmuseum.com/Detail.aspx?CanID=30554\&Member

[13] Can Museum (2016) Pepsi-Cola-355mL-New Look Same Great -United States. http://www.canmuseum.com/Detail.aspx?CanID=76872\&Member $=$

[14] Zaichkowsky, J.L. (2010) Strategies for Distinctive Brands.

[15] Hoek, J. and Gendall, P. (2010) Colors, Brands, and Trademarks: The Marketing (and Legal) Problem Of Establishing Distinctiveness. Journal of Advertising Research, 50, 316-322. https://doi.org/10.2501/S0021849910091476

[16] BBC News (2013) Cadbury Loses Legal Fight over Use of Colour Purple. http://www.bbc.com/news/business-24401249

[17] Brakus, J.J., Schmitt, B.H. and Zarantonello, L. (2009) Brand Experience: What Is It? How Is It Measured? Does It Affect Loyalty? Journal of Marketing, 73, 52-68. https://doi.org/10.1509/jmkg.73.3.52 